\title{
SYNTACTIC VALENCE IN ROLE AND REFERENCE GRAMMAR ${ }^{1}$
}

\author{
Beatriz Martínez Fernández \\ University of La Rioja
}

\begin{abstract}
Transitivity has traditionally been equated with the number of syntactic arguments that a verb takes. However, Role and Reference Grammar (RRG) puts forward a new approach that defines transitivity in terms of macroroles, leaving the notion of syntactic valence aside. It is perhaps for this reason that the notion of syntactic valence has not received sufficient attention in this framework, and, consequently, some inconsistencies have been identified in its definition. To mention only a few, there is no proper definition of the criteria that determine the notion of syntactic valence, and many of the grammatical processes that have some impact on it - the use of the passive voice and imperatives, the presence of argument-adjuncts, or the position of the arguments in the clause-are overlooked. Hence, in this paper I carry out a critical revision of the definition of syntactic valence and aim to set out some guidelines for a more accurate treatment of this notion within the RRG framework.
\end{abstract}

\section{INTRODUCTION}

Transitivity has traditionally been equated with the number of syntactic arguments a verb takes. However, Role and Reference Grammar (henceforth RRG) puts forward a new approach that defines transitivity in terms of macro-roles, leaving the notion of syntactic valence aside. It is perhaps for this reason that the notion of syntactic valence has not received enough attention and some inconsistencies have been identified in its definition. To mention only a few, there is no proper definition

1. This research has been funded through the project ANGI2005/14 (CAR). I would like to thank the two anonymous reviewers for their comments on an earlier draft. 
of the criteria that define the notion of syntactic valence, and many of the grammatical processes that have some impact on it are overlooked by this theory. Hence, in this work I carry out a critical revision of the definition of syntactic valence and aim to set out some guidelines for a more accurate treatment of this notion.

This paper is part of a broader project that analyses break verbs and from which I have taken the corpus. The corpus analysed comprises approximately 1,100 examples of break verbs taken from the British National Corpus (BNC), in both their causative and inchoative versions. To be more precise, I have gathered a total of one hundred examples for each of the twelve verbs selected, picking out twenty random matches for each of the following POS (Part-of-speech) query patterns: finite base forms, past tense forms, -ing forms, past participle forms, and $-s$ forms. The POS is just one of the seven query modalities offered by the BNC, and it searches the BNC for a word with a specific part of speech (POS) code or codes, thus allowing to narrow down my search to the desired patterns. Whether break verbs appear in a mono-clausal sentence or in a subordinate clause of a larger sentence, the only clause under analysis is the one that contains the break verb. This verbal class comprises the following verbs: break, chip, crack, crash, crush, fracture, rip, shatter, smash, snap, splinter, split and tear (Levin 1993: 241).

\section{TRANSITIVITY AND SYNTACTIC VALENCE}

RRG puts forward a new approach to the idea of transitivity that departs from the more traditional purely syntactic views. Van Valin and LaPolla (1997: 149) state that "the number of syntactic arguments alone does not correlate with transitivity" because if transitivity were to be defined according to the number of syntactic arguments of a verb, these should manifest consistent syntactic behaviour, which is not always the case. Example (1) illustrates this idea:

(1) Examples taken from Van Valin and LaPolla (1997: 148)

a. Anna ha mangiato spaghetti per/*in cinque minuti ("Anna ate spaghetti for five minutes.")

b. Anna ha mangiato gli spaghetti *per/in cinque minuti ("Anna ate the spaghetti in five minutes.")

As Van Valin and LaPolla (1997: 148-149) explain, these two examples seem to be transitive. However, only the second example can occur in a passive:

(2) Examples taken from Van Valin and LaPolla (1997: 149, my emphasis)

a. Gli spaghetti sono stati mangiati da Anna in cinque minuti. ("The spaghetti was eaten by Anna in five minutes.") 
b. *Spaghetti sono stati mangiati da Anna per cinque minuti. ("Spaghetti was eaten by Anna for five minutes.")

b'. *Sono stati mangiati spaghetti da Anna per cinque minuti.

If transitivity were simply a matter of how many syntactic arguments a verb can take, the two-argument form of mangiare should manifest consistent behaviour. The same inconsistency is revealed by participial absolutes:

(3) Examples taken from Van Valin and LaPolla (1997: 149, my emphasis)

a. Mangiati gli spaghetti, uscir-ono. ("Having eaten the spaghetti, they went out.")

b. "Mangiati spaghetti, uscirono. ("Having eaten spaghetti, they went out.")

Despite having the same number of syntactic arguments, the constructions do not behave alike syntactically. Consequently, the number of syntactic arguments does not correlate with transitivity. Instead, the notion of transitivity must be built around that of semantic valence (i.e., those arguments which appear in the logical structure of the verb). To be more precise, transitivity will be defined according to the number of macroroles that the verb has, as this is a consistent criterion. In the example above the activity version of mangiare has only one macrorole, as spaghetti is non-referential. This means that mangiare is intransitive in that case, which is in keeping with the fact that it cannot passivize. ${ }^{2}$

\section{SYNTACTIC AND SEMANTIC VALENCE}

The term valency comes from chemistry, where it denotes the capacity of a chemical element to combine with a specific number of atoms of another element, and it was used for the first time within the linguistics field by Tesnière (1959) to denote the ability of words to attach to other words (Benešová 2005: 67). RRG distinguishes between syntactic and semantic valence.

The syntactic valence of a verb is the number of overt morpho-syntactically coded arguments it takes. One can talk about the semantic valence of the verb as well, where valence here refers to the number of semantic arguments that a particular verb can take. (Van Valin and LaPolla 1997: 147)

2. See Van Valin and LaPolla (1997: 149-150), and Butler (2003) for further detail. 
In dealing with these two notions, Van Valin and LaPolla (1997) use the term argument to designate semantic arguments, as is common in many European linguistic theories, while they reserve the label core argument to designate syntactic arguments. As the authors explain, "these two notions need not coincide" (1997: 147). Thus, in a sentence like "It is raining," the semantic valence is 0 , as the verb to rain has no semantic arguments; nonetheless, all English clauses must have a subject; hence, its syntactic valence is 1 (Van Valin and LaPolla 1997: 147).

\section{SYNTACTIC VALENCE}

So far, the notion of syntactic valence may seem to be well defined. However, the corpus has brought to my attention a number of special cases in which the syntactic valence of the verb changes due to certain grammatical processes. The passive is one of them, but it differs from the others - imperatives and clauses with implicit subject (or gapping) - in a significant way: whereas the passive may have an overt argument which does not count for the syntactic valence of the verb because of its adjunct condition, the imperatives and clauses with implicit subject (see (4) below for illustration) have an argument which is not overtly expressed in the syntax. ${ }^{3}$

(4) Imperatives and clauses with implicit subject.

a. <hit text="A73" n="102"> 'Break it up,' said the club wit. (Imperative clause)

b. <hit text="KGL" n=" 68 "> So then break that down, you are talking at least ten pounds a call aren't we? (Imperative clause)

c. $\quad<$ hit text="BM6" n="522"> The plane touched down, bounced up again, slewed sideways and skidded along the runway, breaking up as it did so; the port wing broke off and the rest of the plane turned over on top of it. (Clause with omitted or implicit subject)

d. <hit text=ATE $n=3264>$ Except perhaps, another New Zealander, Professor Ernest Rutherford, who, at Manchester University, succeeded in splitting the atom and in the process started off a chain of events that would be even more shattering than that set off by two shots. (Clause with omitted or implicit subject)

3. Van Valin and LaPolla (1997: 291) treat the by-phrase of passive sentences and adjuncts as peripheral. Thus, for a sentence like 'Sally was surprised by Mary' they put forward the following clause structure: [CL [C Sally [N was surprised]] [Pby Mary]]. 
e. $<$ hit text=AEA $n=360>$ She took two pills from a bottle by the bed on which she had thrown herself and crushed them between the pages of Mansfield Park. (Clause with coordinated or implicit subject)

f. $<$ hit text=AHU n=1572> Over the past two years, Adams has suffered compressed vertebrae, a broken right leg, fractured two ribs and punctured a lung, received two black eyes, a dislocated shoulder, and more recently he smashed his left knee. (Clause with coordinated or implicit subject)

In all cases, the subject can be derived from the context. Thus, in the imperatives (4.a.) and (4.b.), the subject is you, whereas in the clauses with omitted or implicit subject (4.c.) and (4.d.) the subjects are the plane and another New Zealander, Professor Ernest Rutherford, respectively, and in the clauses with coordinated or implicit subject (4.e.) and (4.f.) the subjects are she and Adams, respectively. ${ }^{4}$

This phenomenon of omission can only be explicated around the notion of pivot: Van Valin and LaPolla (1997) reject the universality of the grammatical notions subject and object and suggest that grammatical (syntactic) relations must be defined in terms of restricted neutralizations of semantic roles for syntactic purposes. ${ }^{5}$ The argument that bears the privileged grammatical function is referred to as pivot, and it is construction-specific. In English, the omitted argument in imperatives and participial clauses is the pivot of those constructions, since there is a restricted neutralization with respect to the omitted NP. In other words, both the actor and undergoer arguments can be omitted or matrix-coded. ${ }^{6}$ This is illustrated in (5):

(5) Examples taken from Van Valin and LaPolla (1997: 264)

a. The student watched TV while eating pizza.

b. The student looked out the window while being questioned by the police.

As can be seen in the examples, the missing NP in participial clauses is always interpreted as subject, no matter whether it is actor or undergoer, although in

4. It could be argued that imperatives have no subject but simply an implicit agent. However, the fact that a tag with you can be added supports my view. I thank one of the anonymous reviewers for this idea.

5. See Chapter 6 in Van Valin and LaPolla (1997) for a full account of grammatical relations in the RRG theory.

6. Van Valin and LaPolla (1997: 561) describe two types of matrix-coding constructions: raising to subject (as illustrated in (11.f) below), and raising to object, as in John believes me to bave written that letter. 
English it is necessary to use a passive construction for the latter to be the pivot of the construction.

Going back to the question of the syntactic valence, and in line with the imperatives, the two subordinate clauses in (5.a) and (5.b) will have a syntactic valence of 0 , for although the missing element is the pivot and can therefore be easily identified, it is not overtly expressed in the syntax. Thus, the syntactic valence of the examples in (4) is as follows:

(6)
a. <hit text="A73" n="102"> 'Break it up,' ... (syntactic valence: 1 )
b. <hit text="KGL" n="68"> So then break that down, .... (syntactic valence: 1 )
c. <hit text="BM6" n="522"> .., breaking up as it did so; ... (syntactic valence: 0 )
d. <hit text="FB3" $\mathrm{n}=" 1132 ">\ldots$ succeeded in splitting the atom, ... (syntactic valence: 1)
e. $<$ hit text=AEA $n=360>\ldots$ and crushed them between ... (syntactic valence: 1 )
f. $<$ hit text=AHU $n=1572>\ldots$ a broken right leg, fractured two ribs and (syntactic valence: 1 )

Summing up, the syntactic valence of imperative clauses and clauses with implicit subject is 1 for causative constructions and 0 for the inchoative version of the alternation.

As regards passive constructions, no matter whether the agent is overtly expressed in the syntax or not, the syntactic valence is reduced by 1 with regard to their active counterpart. Thus, in both (7.a) and (7.b) the syntactic valence is 1 , even if the effector is present in (7.a) -erosion - and omitted in (7.b):

(7)

a. $<$ hit text=A6T $n=272>$ The whole place is a shambles of falling rock, soft shaly rock, slaty rock; everything has been split apart by erosion.

b. $<$ hit text=AMB $n=2604>$ The cage was now a few feet off the ground and the noise, which sounded like metal being torn apart, was almost deafening. 
Besides the three phenomena that I have just discussed, there are other factors that play a part in the definition of syntactic valence. One of them is the use of a preposition to introduce the argument(s) of the predicate. Van Valin and LaPolla (1997) and Van Valin (2005) distinguish three types of arguments: direct, oblique, and argument-adjunct. They are illustrated in (8).

(8) Argument types

a. Direct arguments: Javier has already read that book.

b. Oblique core arguments: Ana sent the package to Eli by snail mail.

c. Argument-adjunct: Laura ran to the bus stop.

Direct arguments are those which are morphologically unmarked or not introduced by a preposition (see (8.a) for illustration); in principle, they count for both the semantic and the syntactic valence. Oblique core arguments, by contrast, are marked by a non-predicative preposition in English (see (8.b) above), and they can occur in the core without a preposition (Ana sent the package to Eli by snail mail / Ana sent Eli the package by snail mail). Hence they also count for both the semantic and syntactic valence. Argument-adjuncts are marked by a predicative preposition and cannot occur without it in the core. In this respect, they differ from oblique core arguments, which have the possibility of appearing in the core as direct arguments. Although at first sight they might resemble prepositional adjuncts, they differ from the latter in that they introduce an argument into the core and they either share an argument with the main predicate or they play a part in the logical structure of the verb, as shown in (9). Argumentadjuncts also differ from oblique core arguments in that their preposition is predicative by contrast to that of oblique arguments such as to Mary. This implies that in the case of argument-adjunct prepositions the meaning of the argument is not derived from the logical structure (LS) of the verb.

(9) LS with argument-adjunct:

Ana put the book on the shelf: [do' (Ana, Ø)] CAUSE [BECOME beon'(shelf, book)]

As a result, the presence of an argument-adjunct will change both the semantic and syntactic valence in [+1], although I suggest that the latter be counted separately because, as Van Valin and LaPolla themselves acknowledge, the status of argument-adjuncts as arguments is not 100\% clear. In fact, one of the main problems with argument-adjuncts is that they are difficult to identify. 
Another interesting question brought up by some examples of the corpus which influences syntactic valence is the position in which certain arguments appear. RRG analyses the clause structure as consisting of three layers: clause, core and periphery. Additionally, syntactic positions like the precore slot and the postcore slot are distinguished. The precore slot [PrCS] occurs clause-internally but coreexternally, and it is the position in which question words appear in English. This has certain implications for syntactic valence. Van Valin and LaPolla (1997: 146) define the syntactic valence of a verb as "the number of overt morphosyntactically coded arguments it takes;" however, they do not specify where. What is unclear here is whether they mean the number of overt arguments in the core or also in the pre- and postcore positions, that is, whether question words are syntactic arguments of the verb. That leads us to the fundamental question: what criteria define the syntactic valence of a verb? Van Valin and LaPolla (1997) and Van Valin (2005) do not provide a fixed set of criteria for that. Nonetheless, putting together the information spread throughout their work, the following can be concluded:

1. Syntactic arguments can be either direct or oblique.

2. Syntactic arguments other than the subject must be liable to be passivized.

3. Syntactic arguments must be overtly expressed in the syntax. This leaves out of the analysis the pivots of imperative clauses and of those with omitted subjects or objects even if they are recoverable from the context.

4. Syntactic arguments do not occur in the periphery.

The question now boils down to whether those arguments which are expressed in the precore (or postcore) position count for the syntactic valence of the verb or not. RRG only leaves out explicitly those arguments which appear in the periphery like the by-phrase effector of passive clauses. Given that question words can be semantic arguments of the verb and that they are non-peripheral, it follows that they should be regarded as part of the syntactic valence of the verb. Thus, the syntactic valence of example (10) is 1 [+ 1 argument-adjunct]:

(10) <hit text=EA6 n=1045> "What withstands the blow is good; what smashes to smithereens is rubbish."

These questions sorted out, the analysis has provided some interesting data which deserve some comment. In the first place, Van Valin and LaPolla (1997) and Van Valin (2005) agree that all simple English clauses must have subjects. Thus, a verb like rain with no semantic arguments has nonetheless a syntactic valence of 1 (Van Valin and LaPolla 1997: 147). I emphasize the word simple because the 
analysis has brought forward many cases in which the syntactic valence was 0 (see (11) below). What might at first seem ungrammatical finds an explanation in the fact that most of them are clauses which are part of complex sentences whose subject overtly appears in another clause, as shown in (11.a) and (11.b). In these examples, the subjects of cracking and crash are not overtly expressed in the corresponding clause; however, they can be easily identified in one of the previous clauses in the same sentences. In the case of (11.a), the subject is bars, and in (11.b), him. The only exception to Van Valin and LaPolla's statement would be intransitive imperative clauses such as "Run!", but no similar case has been found in the corpus under analysis.

(11) Examples taken from the corpus with syntactic valence 0.

a. $<$ hit text=A0L n=3271> And Jay was pacing her attic, bars tightening and cracking around a heart that would not stop hurting; she could not lay her body down though it screamed for rest and knots of fury made her neck and shoulders a steely hunch like a vulture.

b. $<$ hit text=C85 n=274> In alarm she glanced back at Samson and saw him hit out wildly, lose his balance and crash back, knocking down the men behind like a row of ninepins.

c. $<$ hit text=A16 n=786> They are generally thicker and harder-fired than wall tiles, to enable them to stand up to heavy wear without cracking.

d. $<$ hit text=CU0 n=1185> As he delivered the first ball of his third over on that fateful sunny afternoon, his left knee split apart, fracturing in two.

e. $<$ hit text $=\mathrm{EDN} \mathrm{n}=1506>$ This was more interesting than being snapped and given a card.

f. $<$ hit text=AJ3 n=608> BROKEN mast, broken rudder and broken boom - everything seems to have snapped in Japans maiden Americas Cup challenge during the past 11 months except the team's spirit.

Notice that, apart from the clauses with implicit subjects discussed at the beginning of this section, there are also examples of clauses with raised subject, as in (11.f), and passive constructions with omitted subject, as in (11.e).

Given that in this work I am only analysing the clauses - not sentences whose predicates contain a break verb, and taking into account that only those arguments which are overtly expressed in the syntax are regarded as part of the syntactic valence of the verb, it is not illogical to define the syntactic valence of verbs such as those in (11) as 0. 
Another interesting issue relates to the lack of correlation between the semantic and the syntactic valence of the verb. As Van Valin (2005: 8) explains, core arguments are related to the arguments in the semantic representation of the verb. However, there are many cases, not only in English but also in other languages, in which such correlation does not hold. That is the case of the dummy it in it is snowing, which occurs in the core but is not a semantic argument of snow (Van Valin 2005: 8). Thus, although the syntactic valence of a verb is semantically motivated, there is no absolute correlation between them. Van Valin and LaPolla (1997: 147) illustrate the non-identity of semantic and syntactic valence in the following table:

\begin{tabular}{|l|l|l|}
\hline & Semantic valence & Syntactic valence \\
\hline rain & 0 & 1 \\
\hline die & 1 & 1 \\
\hline eat & 2 & 1 or 2 \\
\hline put & 3 & 3 or 2 \\
\hline
\end{tabular}

Table 1. Non-identity of semantic and syntactic valence (taken from Van Valin and LaPolla 1997: 147).

Except for rain, all the verbs in the table have a syntactic valence of equal or lower value than the semantic valence. However, in the analysis I have found one example which points to the opposite:

(12) < hit text="CEK" n="339">It broke my heart to see that little face and big eyes.'

While the semantic valence of break in this example is 2 , the syntactic valence is 3: it, my heart, and to see that little face and big eyes. ${ }^{7}$ Hence here we have one more example of the non-identity of semantic and syntactic valence which had not being pointed out before.

7. It must be noted that not all analysts would agree that the subject in (12) is both It and to see that little face and big eyes, though. Quirk et al (1985: 1391) say that It and to see that little face and big eyes are two constituents which form part of the same subject; more precisely, anticipatory subject + postponed subject. On the other hand, Huddleston (1984: 66-68) shows that there is good evidence for taking it as the subject. Thus, this point might need further discussion. I thank one of the anonymous reviewers for this idea. 
I would like to finish this paper by remarking that the majority of prototypical examples of break verbs - that is to say, those whose meaning implies a pure change of state (Levin 1993) - have a syntactic value of 1 in the case of inchoative constructions and 2 in their causative versions. These results only undergo variation when the example is a passive construction, in which case the syntactic valence is reduced by 1 , and when there is some argument-adjunct although, as I have said above, the latter are counted separately because their status as arguments is not completely clear.

\section{SUMMARY AND CONCLUSIONS}

In this paper I have tried to offer an accurate account of syntactic valence within the RRG theory. First, I have carried out a critical revision of this notion, pointing out how certain grammatical processes such as the use of passives, imperatives, and clauses with implicit subjects (or gapping) affect the definition of syntactic valence. Very briefly, the syntactic valence of imperative clauses and clauses with implicit subject is 1 for causative constructions and 0 for the inchoative version of the alternation. As regards passive constructions, no matter whether the agent is overtly expressed in the syntax or not, the syntactic valence is reduced by 1 with regard to their active counterpart. The occurrence of an argument-adjunct will change both the semantic and syntactic valence in [+1]. This is summarised in the table below:

\begin{tabular}{|l|l|l|l|l|}
\hline & $\begin{array}{l}\text { Basic syntactic } \\
\text { valence }\end{array}$ & $\begin{array}{l}\text { +Argument- } \\
\text { adjunct }\end{array}$ & Passive & $\begin{array}{l}\text { Imperatives and } \\
\text { clauses with } \\
\text { implicit subject }\end{array}$ \\
\hline Inchoative clause & 1 & $(+1)^{8}$ & $\nexists$ & -1 \\
\hline Causative clause & 2 & $(+1)$ & -1 & -1 \\
\hline
\end{tabular}

Table 2. Syntactic valence of prototypical examples.

With this information in mind, I have proposed the following criteria for a precise definition of syntactic valence:

8. I use brackets because this argument is added to the already existing syntactic valence of the verb, but separately. For example, when an argument-adjunct is added to a predicate of basic syntactic valence 1 , the resulting syntactic valence is $1(+1)$. 
1. Syntactic arguments can be either direct or oblique.

2. Syntactic arguments other than the subject must be liable to be passivized.

3. Syntactic arguments must be overtly expressed in the syntax. This leaves out of the analysis the pivots of imperative clauses and of those with omitted subjects or objects even if they are recoverable from the context.

4. Syntactic arguments do not occur in the periphery.

To these, two more criteria can be added now:

5. Question words, which appear in the pre-core slot position, are also to be regarded as part of the syntactic valence of the verb.

6. The valence of clauses with raised subject and passive constructions with omitted subject is reduced by 1 with regard to their non-raised and active counterparts, respectively.

To round off, in this paper I have carried out a critical revision of the definition of syntactic valence within the RRG theory and I have set out some guidelines for a more accurate treatment of this notion, focusing on the main grammatical processes that have determined it.

\section{REFERENCES}

Benešová, V. 2005. "Valency and Semantic Features of Verbs." WDS’05 Proceedings of Contributed Papers. Ed. J. Safrankova. Prague, Czech Republic: Charles University, Faculty of Mathematics and Physics. Part I: 66-71. Accessed 15 April 2007 at http://www.sil.org/Linguistics/GlossaryOfLinguisticTerms/WhatIsValency.htm.

Butler, C. 2003. Structure and function: a guide to three major structuralfunctional theories. Amsterdam; Philadelphia: John Benjamins.

Huddleston, R. 1937. Introduction to the grammar of English. Cambridge: Cambridge University Press.

Levin, B. 2003. English Verb Classes and Alternations: A Preliminary Investigation. Chicago and London: The University of Chicago Press.

Quirk, R. S. Greenbaum, G. Leech and J. Svartvik. 1985. A Comprehensive Grammar of the English Language. London: Longman.

Tesnière, L. 1959. Éléments de syntaxe structurale. Paris.

Van Valin, R. D. and R. J. LaPolla. 1997. Syntax: structure, meaning and function. Cambridge: Cambridge University Press.

Van Valin, R. D. 2005. Exploring the syntax-semantics interface. Cambridge: Cambridge University Press. 